\title{
THE SETTING UP OF A GIS FOR THE GENERAL POPULATION AND HOUSING CENSUS
}

\author{
Si youcef, Kamel1*; Boukerch, Issam1; Hocine Imane1; Benabdelkader Aicha1 \\ Algerian Space Agency, Space Techniques Center, Arzew, Alegria \\ kamelsiyouceftopo@gmail.com
}

Commission IV

\section{KEY WORDS: ONS, RGPH, GIS, DBMS}

\begin{abstract}
:
The general census of population and housing is a statistical operation which consists in counting all the populations and all the dwellings of a given territory at a precise date which must produce data of interest to $t$ users and this is the essential statistical purpose of their execution. Each operation executed during a census must have the goal of producing results that meet the needs of the users. The information collected in this way has several interests of the country. The census in Algeria is taken by the National Statistics Office (ONS) which is preparing its sixth General Census of Population and Housing (RGPH). The census is organized in four steps that are: Cartographic Preparation, Staff Training, Execution of the RGPH, and Exploitation.

Algeria, in this year 2020 is in phase of preparation of the RGPH, this phase relates to the cartographic aspect and our contribution will relate to the elaboration of a geographic information system (GIS) This phase concerns the cartographic aspect and our contribution will focus on the development of a geographic information system (GIS) allowing the management of the first stage of the RGPH operation, the latter having a mainly cartographic aspect. The design and production of this BDG were made on the basis of the reflections resulting from a careful study of the manuals for this operation and interviews with the local managers of this. In this perspective, a bibliographical study was made to be inspired by the experiences of other countries, and to gain some insight into the techniques used in them.

The tools offered by Open Source software represent an important alternative to find a solution to this problem. The information collected during this preparation phase is also important and is very useful for local actors to better understand the space and distribution of the population, which will allow a more rational management of resources.

The objective of this paper is focus of the integration of spatial techniques in the census in Algeria while presenting the national office of statistics. An overview of census techniques in different countries is made to illustrate the know-how of this national office. The purpose of the general population census is to give the state a means that cannot be circumvented so that it can plan, among other things, the budget for the coming years according to the distribution of the population and its demographics.
\end{abstract}

\section{INTRODUCTION}

The general population and housing census is an operation of national interest which is of particular importance. The census should produce reliable data of interest to different users. In Algeria, this task is carried out by the National Statistics Office which manages the general census of the population and the Housing of the cycle of 2020. Each operation carried out during a census must aim to lead to results which meet user needs.

It examines the methodology of the general census of the population and the habitat with the cartographic preparation in Algeria. The success of the population and housing census requires the collaboration of all the actors involved in its various phases of preparation, execution and operation

Through this paper, we have shown that the first phase of the census and its results can be integrated and managed by a geographic database. The information collected in this phase is of potential interest in other applications such as local planning and population distribution within the municipality. The system as designed is of interest during and after the execution of the first phase and highlights the value of using this information in the management of local authorities.

Requests have been developed to interrogate the geographic database, and make adequate decisions such as evaluating national needs and consulting socio-demographic indicators for the supervision and evaluation of the different socio-economic development programs for the whole country while having a look at the specificities of each region.

The success of the census operation is not an end, but a source of data to be analyzed and published within a reasonable period of time after the collection operation.
In order to organize the data collection and to avoid oversights, omissions and repetitions during the general population and housing census, the preparatory phase must be conducted with great care in a serious, controlled and efficient manner.

In this respect, the need for spatial information management is very present and to satisfy it, the use of GIS tools is proposed as a solution that makes access to information easier, faster and without errors.

The first question that is asked after the consultation and the study of the example provided is: will the solution for using the GIS tools meet the needs of the technical services at APC to complete the preparatory phase?

\section{METHODOLOGICAL APPROACH}

The methodology used for the realization of the proposed solution is based on a bibliographical research on the following websites, Plus an in-depth reading of the training manuals for the agents and organizers of the RGPH operation. The RGPH services in the 3 communes were also contacted

This approach with the agents of the RGPH and the understanding of the work they are in charge of, Allowed us to understand the RGPH procedure and to propose a conceptual data model that organizes and manages the preparation phase of the RGPH work.

\subsection{Census Cartographic Preparation}

The cartographic preparation of the census operation whose objective is to facilitate the work of the census execution staff in the ground by dividing the communes into census units or 
districts. This is a very important step for the success of the general population and housing census(Guide de la cartographie de recensement ONS 2008), This cartographic preparation operation is organized in four phases.

\subsubsection{First phase: Cartographic update and filling in the construction forms}

Consists of updating or developing the communal cartographic base and filling in the construction forms with reference to the RGPH 2008 file. It is a construction counting. (Guide de ons 2008)

The main basis for this preparation will be the RGPH-2008 cartographic coverage that the O.N.S. will make available to each commune before starting the operation. A file is then given to the census taker, it must be composed of:

1. The summary plan of the commune

2. The old agglomeration plans

3. The identical forms of the constructions to be filled in

4. District Books

During this preparatory phase, it is a question of:

The updating of the summary plan of the municipality (to note the positioning of the housing, artificial and natural elements) and the updating of the plans of the agglomerations (limits of the agglomeration, the representation of all the units) and all the roads with the exact names, the reference points), to identify and counting all the constructions located on the territory of the municipality by filling in the Identification forms of the constructions (Guide de ons 2008)

As a general rule, it should start the cartographic update of the municipality by the scattered area, then the secondary agglomerations and finally the chief town agglomeration.

\subsubsection{Phase Two: Finalization of the Plans and Updating of the District Divisions}

In the first phase, we established the summary plan of the municipality and the updated plans of the agglomerations, where all the necessary indications for the division of the municipality into districts are given (Guide de ons 2008).

\subsubsection{Making the plans clean :}

We start with the scattered zone, then the secondary agglomerations and finally the main town agglomeration.

\section{a) Drawing of the summary plan of the municipality:}

The plan of the scattered zone is generally on a scale of $1: 50,000$ to the north of the country, $1: 100,000$ for the high plateaux and 1:200,000 for the communes in the south.

\section{b) Drawing of agglomeration plans:}

Agglomeration plans must be on a large scale (1/2000 1/5000).

\subsubsection{Division into districts:}

This phase will consist of dividing the plans into census districts. A district is a portion of ground of the territory of the commune, of a suitable size for a census taker to fully investigate it during the census period (15 days).
Districts must be numbered from 1 to $\mathrm{n}$ in the municipality. We start by numbering the districts of the scattered zone, then those of the secondary agglomerations and finally those of the main town.

The ideal size of a district is the number of people that a census taker can survey during the time frame for data collection:

- 900 to 1200 people in an agglomerated district.

- 500 to 600 people in a scattered district.

In the case of cities that are completed or in the process of being completed and that are likely to be inhabited before the date of execution of the RGPH, the ideal size of the districts in terms of housing::

- 150 to 200 housing units in agglomerated district.

- 80 to 100 homes for a scattered district.

Make many scenarios of division into districts in order to have districts of more or less homogeneous size.

\subsubsection{Third phase: Numbering units and districts:}

At this stage of the work, the districts are cut out, the construction sheets are filled in, and the district and block numbers are final. It is a question of affixing them on the walls of the constructions (Guide de ons 2008).

\subsubsection{Fourth phase: Census of the district book:}

The district book is a basic document of the general population and housing census. It is the result of the entire cartographic preparation phase of the RGPH and the indispensable working document for the enumerator.

Two types of district books are provided, one of the districts in the agglomerations and another for the districts in the sparsely populated area. Each district book is filled in from the corresponding construction forms (Guide de ons 2008).

\subsection{The Tools and Data Sources Used:}

The dataset consists of two districts with the numbers 38 and 40. These districts contain 222, 196 constructions successively located in the center of Arzew. The two datasets given include the construction forms of the two districts, the sketches of the units as well as the Agglomeration plan. This data has been made available to us by the RGPH department of Arzew. To carry out the work, we downloaded the cartographic background and the

\subsection{Open source software was used:}

A DBMS, PostgreSQL which is augmented by the PostGIS module allowing the processing of geographic information, Qgis which is a GIS software used for the acquisition, manipulation and viewing of data.

\subsection{Conception of the database}

\subsubsection{Data dictionary preparation}

In order to satisfy the needs of the end users in the design of the application, a list of entities and attributes has been chosen. During the conception phase, the specified data are registered in a dictionary. This dictionary is an important tool because it is the reference for all the studies carried out. 


\subsubsection{The Conceptual Data Model (CDM):}

In this step the data were written in a formal way in order to use them in an information system to facilitate comprehension. After a review of the operation manuals and visits to the people in charge of the operation in the municipality, the following model was established:

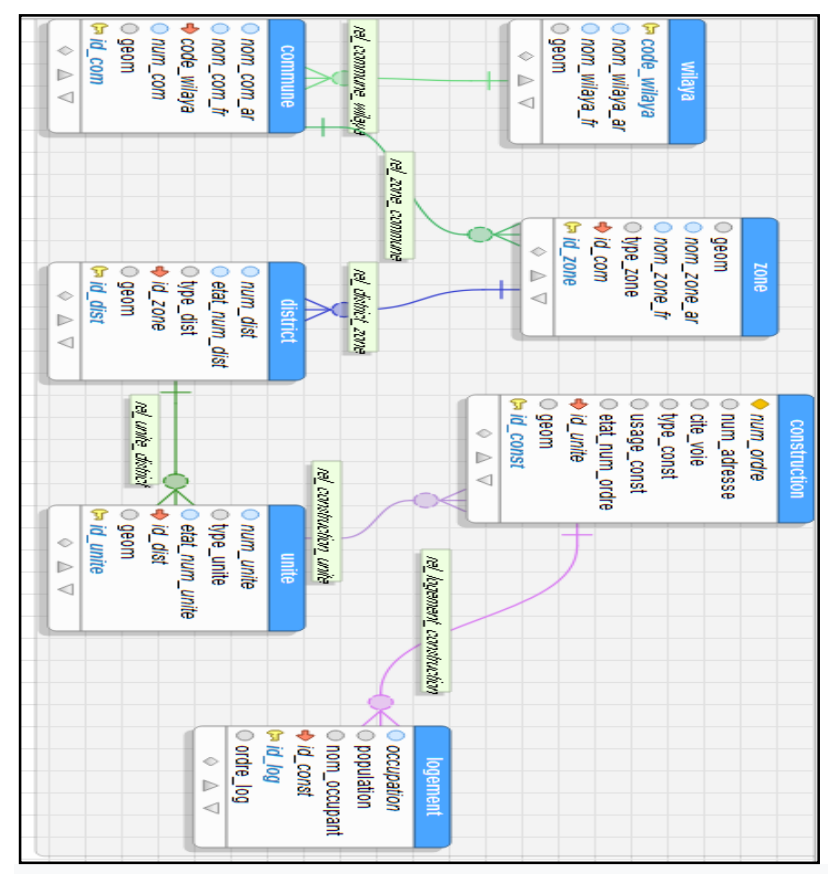

Figure 1. The conceptual data model

This modeling of the MCD was performed by the PostgreSQL database modeling tool (PgMoldeler).

\subsection{Implementation of the database:}

For this implementation, the following steps were taken:

1. Verification and validation of the model obtained and that all entities have a primary key and that all tables are well related to each other through foreign keys.

2. The creation of a virgin database using the PgAdmin tool.

3. For the database to work spatially we must add the PostGIS spatial extension after the installation with the command: Create extension PostGIS

4. The addition of data structures: tables, constraints (primary key, foreign key, check, unique, not null) followed by the addition of triggers and views using the PgAdmin 4 interface.

To guarantee the integrity of the database and to facilitate its usage, triggers and constraints have been created, for example in the district and zone table

5. Adding a primary key as a unique identifier for the rows of the table

6. Adding a foreign key in the district table «commune_code_wilaya_fkey» which specifies that the value in the id_zone column must match the value appearing in a row of the field table

7. Adding a check constraint « etat_num_district » which specifies that the column etat_num_dist includes only the two following values: prove or def.

8. The addition of a Unique constraint that guarantees that the order number must be unique.

9. The addition of unique_index: the index acl_hcl_uni_com is created to impose the Unicity of type_zone ACL or hcl in the municipality.

Create unique index acl_hcl_uni_com On zone (id_com)

Where type_zone='acl' or type_zone='hcl';

Figure 2. Representation of Unicity index.

10. the trigger geom_zone_dans_geom_com verifies that the geom type polygon in the zone table is completely contained in the geom type polygon of the commune table.

CREATE OR REPLACE FUNCTION fc_geom_zone_dans_geom_comO RETURNS TRIGGER

LANGUAGE PLPGSQL

AS

$\$ \$$

If new.geom in (selec

from zone

inner join commune

else

return new ;

on st within(zone.geom,commune.geom)) then

else

raise exception 'chaque zone est contenue dans une commune'; end if;

RETURN NEW:

END;

$\$ \$$.

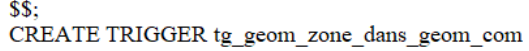

after insert or update of geom

ON zone

FOR EACH ROW

EXECUTE PROCEDURE fc_geom_zone_dans_geom_com();

Figure 3. Trigger for verification of geometry

The same aspect is used for the other tables in the database, the following figure represents the complete model after adding all constraints, relational and triggers. 


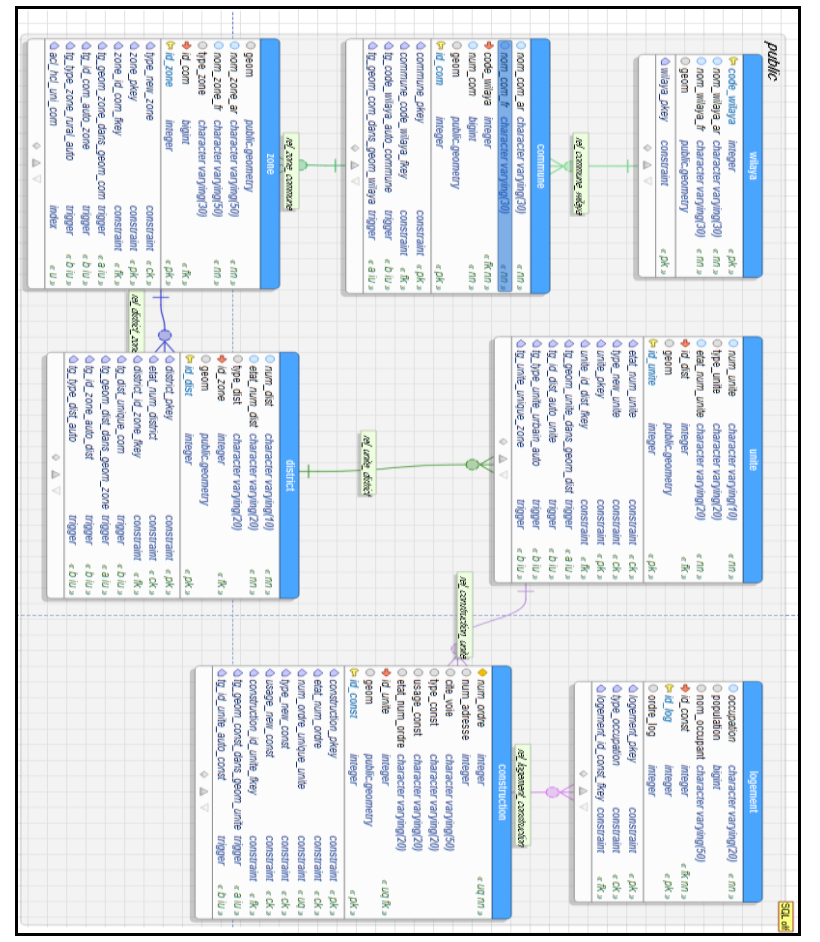

Figure 4. conceptual data model after adding constraints.

11. The addition of the "views": We used the virtual tables in the database for different reasons such as: The aggregation of the normalized tables in a single virtual table. Acting as a stored request to avoid writing SQL several times, and to answer several questions among the questions that can be answered by the views we have created:

- Agglomerated districts where the population is greater than 1,200 and dispersed districts where the population is greater than 600 .

- Agglomerated districts where the number of the population is in the range [900-1200] and dispersed districts where the number of the population is in the range [500-600].]

- The number of the population for each unit

- The number of persons for each construction

- The number of population in each district

- The units that belong to each district

- Units with a provisional unit number

- Rural units

- Agglomerated units

\subsection{Cartographic aspect}

The base, thus created has the structure to store information. Part of this information is geometric. So it is necessary to inform the geometry type field of each table.

After connecting our database via Qgis, we execute the following steps:

1. The import of Shape file "commune_shp" which contains the administrative limits of the communes of Algeria while bringing modifications at the level of the columns of the attribute table for its adaptation with our database. This is followed by an insertion of all the columns of the table "commune_shp" with their corresponding table in our database.
2. A union is made by an SQL request from the wilaya code to extract the geometry of the wilaya table and create a view. This table is inserted in the corresponding table of the database in order to materialize $\mathrm{i}$

3. The import of a recalculated background map

4. Digitizing and filling in the entities: unit, construction, district, zone on the background image from the ONS plans and the field forms that are filled in by the census taker.

\subsection{The cartographic aspect and visual variables:}

Conventional or digital maps remain the only document that communicates very large amounts of spatial information rapidly and precisely.

The content of the map is produced to be completely in line with the objective and satisfy the needs of the preparatory step of RGPH

In order to eliminate the clutter of the map, different scales of visualization have been used while incorporating a symbology (colors, to facilitate reading and interpretation), among the scales the following have been used:

1. The National scale: to visualize the totality of the willayas from $1 / 30.000 .000$

2. at the wilaya scale: to view the willaya concerned from 1:30000 000 up to $1: 1000000$

3. at the communal scale from $1: 1,000,000$ to $1: 25,000$ to display the geometry of the communes

4. Zone scale: from $1: 50,000$ to $1: 10,000$ to view zone geometry

5. District scale: from $1: 15,000$ to $1: 2,000$ to view district geometry.

6. Unit scale: from $1: 5000$ up to 1 to view unit geometry.

7. construction and road scale from 1:2,000 to 1 to view door geometry

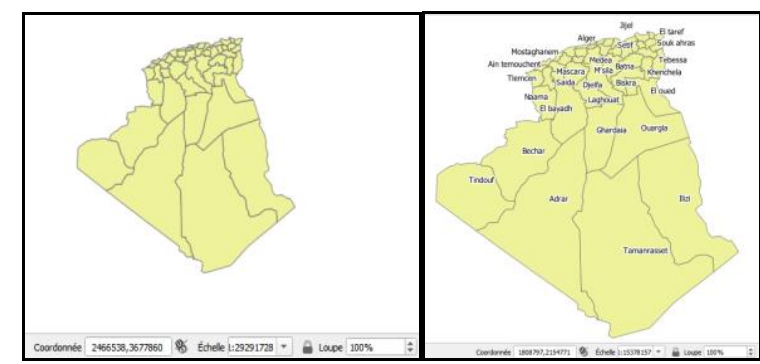

Figure 5. Example of multi-scale viewing.

\subsection{Conventional signs and symbology:}

The map should be simple to read and not cluttered with information. The use of colors is a factor in answering this problem. The color must directly or intuitively show us the object in question, for example a river must be in blue.

To enrich the plans and facilitate consultation and orientation, additional information must be added such as remarkable buildings, public edifices, street bodies in order to facilitate the orientation of the user.. 


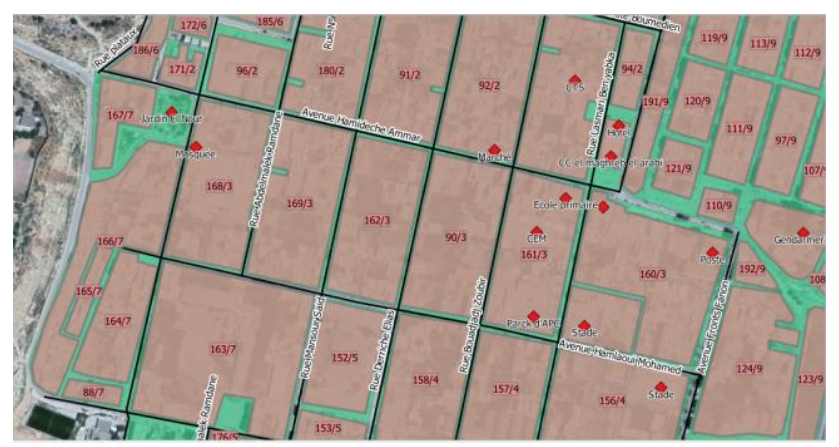

Figure 1. Geometrical details and application of symbology.

\subsection{The resulting products:}

\subsubsection{The views :}

The creation of views answers several questions that help the ONS officer make decisions. These views are designed to extend to the questions cited in the conception part of the database.

The views implemented in the GDB are represented in the following figure:

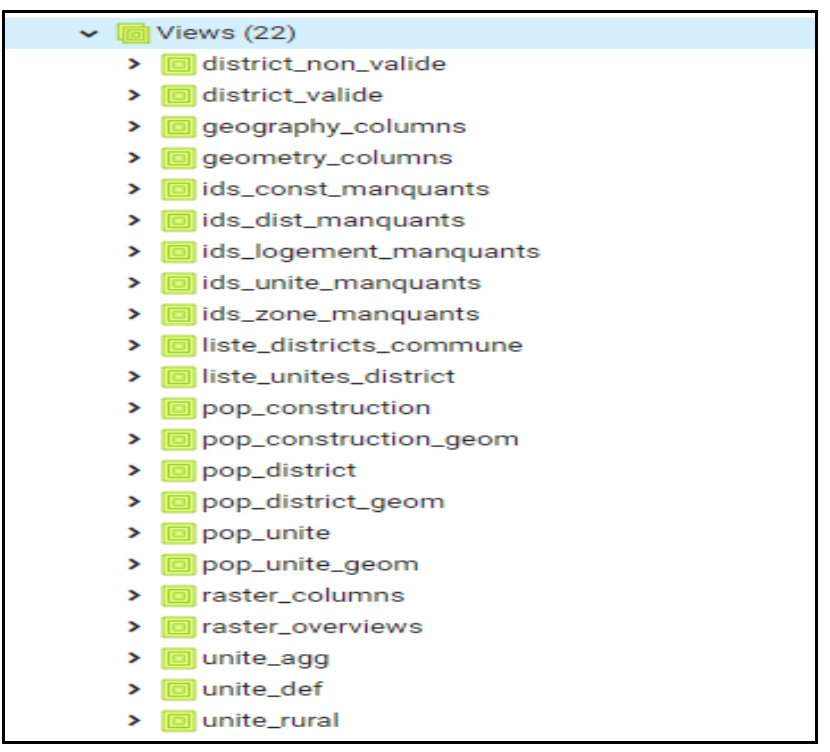

Figure 2. Implemented views.

The following section presents the details of some views as examples:

\section{Views: district_non_valide}

This is an attribute result view that displays invalid districts and requires a new district division to be created.

SELECT district.id_dist,

pop_district.pop_dist

FROM pop_district

JOIN district ON pop_district.id_dist $=$ district.id_dist

WHERE (district.type_dist= 'eparse' AND

(pop_district.pop_dist > 500 OR pop_district.pop_dist $<600$ ))

OR (district.type_dist = 'agg' AND (pop_district.pop_dist >

900 OR pop_district.pop_dist< 1200));

\section{Views : pop_unite_geom}

It is a view with an attribute and geometric result. It gives the number of population in each unit.

Create view pop_unite_geom as

SELECT pop_unite.id_unite,

pop_unite.pop_unite,

unite.geom

FROM unite

JOIN pop_unite

ON unite.id_unite = pop_unite.id_unite;

\section{Vue Unite_agg}

This is a view that presents the units in the agglomerated zone

create view unite_agg as

SELECT unite.num_unite,

unite.type_unite,

unite.id_unite

unite.id_dist

FROM unite

WHERE unite.type_unite= 'urbain' ;

\subsubsection{Production of the Atlas:}

The atlas have been defined for the automation of the serial production of maps of different geographical entities. Then, once the layout is completed for a given entity, an Atlas is generated.

In this part of production different atlases have been generated as an example (atlas of the municipality, atlas of the district atlas of units.... etc..).

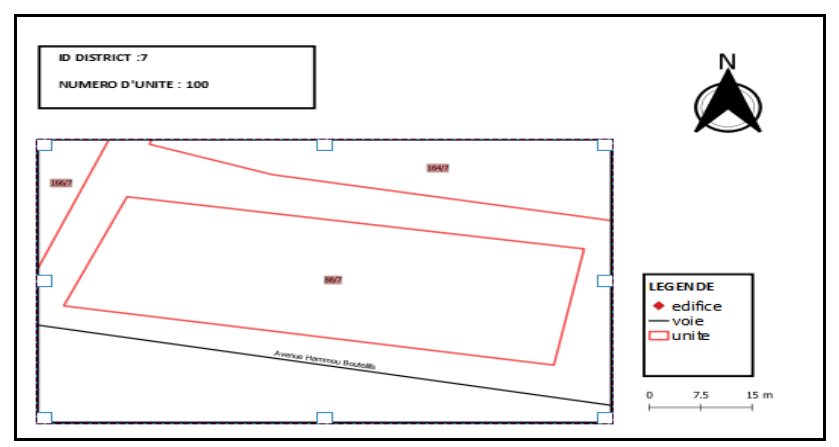

Figure 3 . An example of an atlas of the "units" object.

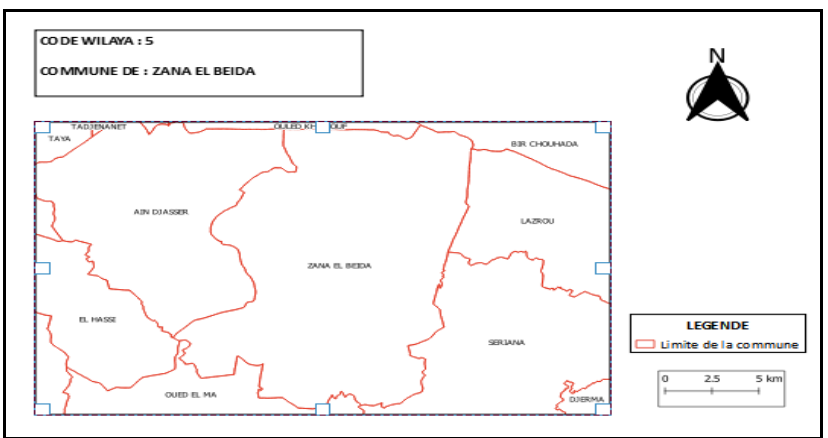


Figure 4. An example of an atlas of the " commune " object.

The series of maps relating to the islet was used by the census takers to locate the site and to collect information relating to the access of buildings.

\subsection{Potential for utilisation:}

The results of our work are not limited to ensuring and facilitating the smooth running of the preparatory step of RGPH. However, these results can be very useful and practical in realistic approaches and analyses that help decision-making at the commune level because information on the distribution of the population and constructions is available.

In order to demonstrate the force and the potentiality of the use of this information, two thematic maps have been created, the first one is to visualize the density of the properties (construction) in the communal space and the second one is to visualize the density of the inhabitants in the introduced part. For this we use the layer "pop_construction_geom" which is a view previously created and stocked in the database

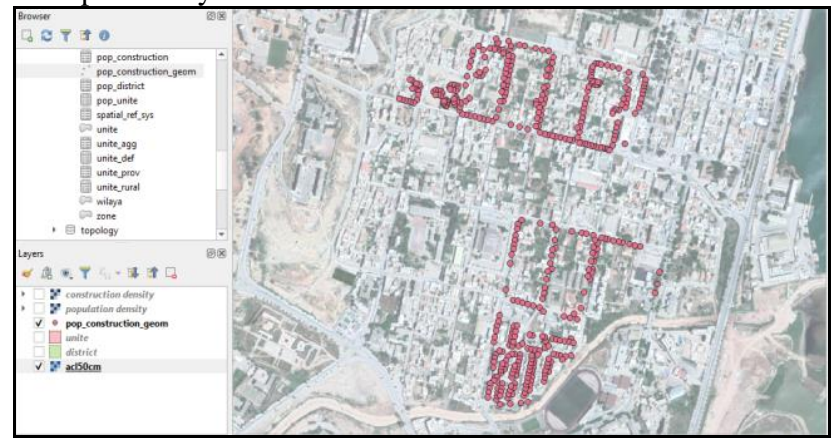

Figure5. Data related to the "pop_construction_geom" view.

The first map shows the visualization of the distribution of properties at the commune level, which is collected in the field by the agent of the census.

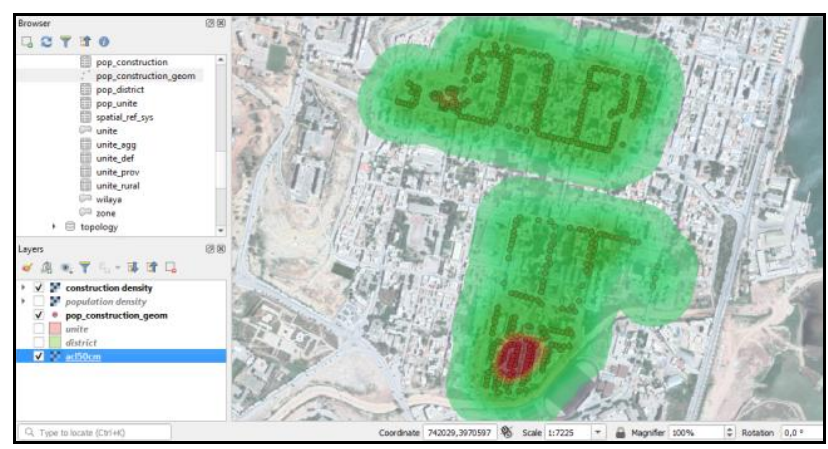

Figure 6. Representation of the density of construction.

The second map represents the visualization of the population distribution at the community level that is collected on the ground by the census taker

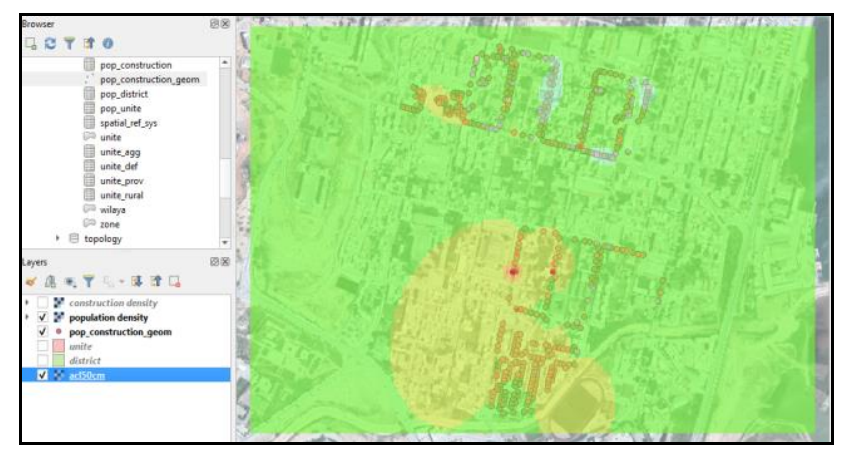

Figure 7. Representation of Population Density.

\subsection{Comparison of results with other}

\begin{tabular}{|l|l|}
\hline Country & $\begin{array}{l}\text { The methodology for managing the preparatory } \\
\text { phase of the census }\end{array}$ \\
\hline American & $\begin{array}{l}\text { In recent censuses, the United States relied heavily } \\
\text { on modern technology. } \\
\text { The biggest tech upgrade for } 2020 \text { is that this is the } \\
\text { very first census that can be taken online. Most } \\
\text { American households receive an invitation by mail } \\
\text { to log in and complete the census. Only households } \\
\text { that have not completed the census receive a paper } \\
\text { questionnaire. The hope is that the online census } \\
\text { will improve response rates and reduce the cost of } \\
\text { sending enumerators for follow-up. }\end{array}$ \\
\hline Morocco & $\begin{array}{l}\text { The use of the GIS tool for the purposes of } \\
\text { censuses and surveys, up-to-date and good quality } \\
\text { maps and geographic data; to set up geographic } \\
\text { databases comprising both geography and attribute } \\
\text { data promote spatial analysis; and to provide new } \\
\text { solutions for the development and management of } \\
\text { area sampling frames and the drawing of samples } \\
\text { for the needs of surveys }\end{array}$ \\
\hline Gabon & $\begin{array}{l}\text { design of the database, and the integration of data } \\
\text { from the field and the layout and edition in A3 and } \\
\text { A4 format of the maps }\end{array}$ \\
\hline
\end{tabular}

\section{CONCLUSION}

The implementation of a geographic information system is a major asset in our contemporary world. The role of this information system will therefore be to collect, store, convey and provide information related to the functioning of an organization.

In this article, we have briefly described the process of realization of our application by specifying the database conception and implementation environment

We noted the importance of the GIS tool in the organization of this preparatory operation by facilitating the collection of information and ensuring the optimal organization by integrating this information into a geographic database.

Due to the fact that the structuring and constraints are made on the basis of real information, the seizure of the real information archived by the service of the commune of two districts passed with any problem, which makes the integration of this system in the real operation perfectly possible

We also note that the information collected during this phase can respond to any number of local or even regional decision support needs if the system is used on a larger scale. 
At the end of this work, we believe that we have achieved our objective, namely:

On the one hand, to provide the ONS with a working tool, which by its functions will meet, at least we hope, certain expectations of officials to better manage and process information relating to the General Population Census and Habitat (RGPH).

We do not pretend to have produced perfect software that is free from all criticism. Therefore, criticism and suggestions are welcome. We are aware of the need to make improvements as the needs of the user evolve.

This less obvious experience at the beginning, is a source of creativity and is fascinating, it is an art since it allowed us to have more or less a glimpse of what awaits us in our professional life.

To finish, far from being exhausted, this article made us discover the immensity and the complexity of the realization of a computer application that only the conviction, the patience, in a word the courage make it possible to overcome

The success of the census operation is not an end in itself, but a source of data to be analyzed and published within a reasonable time after the collection operation.

\section{REFERENCES}

Bahlouli, H. M .,2010 L'enquête post-censitaire une mesure de l'exhaustivité et de la qualité de la collecte des donnéesRecensement réalisé en Algérie.

Bardinet.,C,Roger., G.,1981. La Cartographie des recensements.

Direction technique statistique régional agricole et de la cartographie de l'ONS.,2008 Guide de la cartographie de recensement[16]

Institut national de la statistique, Mali .,2016. stratégique de la cartographie 5ème RGPH .

\section{Guide de l'ONS 2008}

Nations Unies. Division de statistique.,2002. Manuel d'organisation des recensements de la population et de l'habitation, no 83 .

Tabutin, D., Casseli, G.,2006.Les systèmes de collecte des données en démographie, Démographie, analyse et synthèse, vol. 8 , p. 28.

Unies, N.,2020 Principes et recommandations concernant les recensements de la population et des logements. Troisième révision, New York, Nations unies, Département des affaires économiques et sociales, Division statistique, Études statistiques, Série M, n, vol. 67, p. 03.

Unies, N.,2008 Principes et recommandations concernant les recensements de la population et des logements. Deuxième révision, New York, Nations unies, Département des affaires économiques et sociales, Division statistique, Études statistiques, Série M, n, vol. 67.

United Nations., 1986. Atelier régional des Nations Unies sur le traitement des données du recensement 